\title{
Organizational Entrepreneurship as a Prerequisite for the Management of High-Efficiency Organization
}

\author{
Joanna Gajda \\ Czestochowa University of Technology, Częstochowa, Poland
}

\begin{abstract}
This article reviews a few definitions of organizational entrepreneurship in order to define its essence. Then, the article focuses on internal conditions conducive to the development of entrepreneurial attitudes and behaviors. It also presents selected issues related to the impact of corporate entrepreneurship on the effectiveness of the organization.
\end{abstract}

Keywords: organizational entrepreneurship, effectiveness, management

\section{Introduction}

Currently, in reality characterized by the rapid pace of change, the activity of entities involved in economic processes is becoming increasingly important. This activity is focused on the tasks that lead to achieving goals. Therefore, innovative methods of the functioning of the organization are needed. These methods should involve the search for new ideas, which can be used to obtain permanent position on the market. One of the possibilities leading to the implementation of creative solutions is to develop entrepreneurial attitudes and innovation of employees that will increase the probability of noticing available opportunities. From the entrepreneurial point of view, efficiency of the organization is important and business owners should pay attention to the conditions underlying this valuable skill that indicates the ability to understand needs of the market, their forecasting, and even overtaking.

The aim of this article is to present the reasons for basing the management of the organization on the elements of entrepreneurship, which will increase its effectiveness.

\section{The Theoretical Basis for Building Organizational Entrepreneurship}

When talking about the concept of "entrepreneurship", it must be emphasized that it is an ambiguous and multi-dimensional category, so it can be interpreted differently. Literature provides many definitions and references to this issue. Entrepreneurship, in the definition of Bratnicki (2009), means that there is a specific course of action whose essence is to focus on development, taking reasonable risks, learning from failures, and promoting flexibility and innovation. As rightly pointed out by Bratnicki, Zbierowski, and Kozłowski (2007), entrepreneurial activity is the process of making sense, accompanied by discovering and understanding, that allows to shape the reality, thanks to the developed operations strategy. According to Baron (2012, p. 4), entrepreneurship involves "the use of human creativity, knowledge, and energy to develop something new,

Joanna Gajda, Ph.D., Czestochowa University of Technology, Częstochowa, Poland.

Correspondence concerning this article should be addressed to Joanna Gajda, Bialska 59/3, 42-200 Częstochowa, Poland. E-mail: joannagajda@vp.pl. 
useful, and better than what already exists and which creates some kind of values (social and economic)". As noted by Walczak (2010), entrepreneurship manifests itself in actions leading to coordination of the organization's resources and behaviors of its members, whose important motive is to seek benefits. This directly impacts not only the current activities of the organization, but all the possibility of its further development (Walczak, 2010). On the basis of these few opinions relating to the definition of entrepreneurship, it can be concluded that entrepreneurship is associated with procedures aimed at achieving success. In addition, entrepreneurship means the transition from pre-existing status quo to something new and unique in its approach, and its results should be sought in the creative use of opportunities through the innovative use of financial and material resources and rational coordination of the resources of individuals, which are managed by the organization (Klasik, 2006).

Literature of organizational entrepreneurship provides a description of various types of entrepreneurial activity of the organization. Based on the achievements of the modern theory of corporate entrepreneurship, the activity can be divided into three types. This division sets out three strategies of action for the implementation of corporate entrepreneurship. Table 1 presents the newest division of the types of actions.

Table 1

Types of Entrepreneurial Activities in the Organization

\begin{tabular}{|l|l|l|l|}
\hline K. Vesper's typology & The newest typology & $\begin{array}{l}\text { The necessary level of } \\
\text { autonomy of employees }\end{array}$ & Key players \\
\hline $\begin{array}{l}\text { Autonomous taking of new } \\
\text { initiatives; } \\
\text { New strategic direction }\end{array}$ & $\begin{array}{l}\text { New business enterprise; } \\
\text { Entrepreneurial orientation; } \\
\text { Entrepreneurial management }\end{array}$ & $\begin{array}{l}\text { Medium; } \\
\text { Low }\end{array}$ & $\begin{array}{l}\text { Entrepreneurial teams; } \\
\text { Managers }\end{array}$ \\
\hline Initiative from below & Intrapreneurship & High & Employees \\
\hline
\end{tabular}

Source: Żur (2008).

As noted by most authors, the bond connecting all of the presented types of activity is the end result in the form of identical manifestations of corporate entrepreneurship proposed by Żur (2008). She took into account: pro-activity (on one or many levels of the organization), risk-taking, and diffusion of innovation. One of the types of entrepreneurial activity is the new economic initiatives. American authors are unanimous about the fact that new economic initiatives underlie the intra-organizational entrepreneurship (Żur, 2008).

Entrepreneurial orientation can be seen as a key differentiator of entrepreneurship. Its intensity is determined by assessing the level of the risk factors involved and thus innovation, pro-activity, and the risks (Nogalski \& Karpacz, 2011). However, this does not mean that the increase in the number of elements comprising it has an impact on the growth of entrepreneurship. In this case, the optimal solution can be a balanced process in which the intensity of the level of entrepreneurship depends on the particular situation (Dyduch, 2007).

It is worth remembering that entrepreneurial orientation is a social process carried out through the members of the organizations whose entrepreneurial behaviors transform the organization as a result of going beyond schematic actions (Bratnicki, 2009). These behaviors are manifested in the ability to create opportunities and move towards maintaining a competitive advantage (Gabryś, 2015). An entrepreneurial man is able to see opportunities in his environment and turn them into profit (Grzegorczyk \& Romanowska, 2002). Seeking opportunities is associated with aiding the strategic operations by creating a new venture understood as a new activity, especially by rebuilding key assumptions relating to business theory (Guth \& Ginsberg, 1990). 
The progressive pace of change that is taking place in the external environment forces companies to shape their entrepreneurial behaviors on two levels-employees and executives of different levels. Speaking about internal (corporate) entrepreneurship, it is worth remembering that the main character making a significant contribution to promoting the idea of entrepreneurship is an entrepreneur (internal), who leads the project from the inception of a new idea until its commercialization (Pinchot, 1999). Therefore, a good entrepreneur should have certain abilities in the implementation of projects, such as (Czerniałowicz, 2011):

- the ability of creative thinking, introduction of new solutions from planning activities to implementing them;

- seeing the need for change, ability to initiate it, and high activity in the process of transition;

- the need for a relative sense of security created by the organization.

Having such staff will bring the organization the greatest benefits. They oppose to maintaining the status quo that protects the organization against bureaucracy and thus against the stagnation of staff. Internal entrepreneurs take responsibility for creating entrepreneurial behavior. Thanks to their attitude, the "spirit of enterprise" grows within the organization. In addition, they supply the organization with creative possibilities (Piecuch, 2011). To achieve this goal, they can use their strengths, such as (Stoner, Freeman, \& Gibert, 1999):

- a strong need for achievements and the ability to take initiative;

- internal locus of control over their own lives;

- willingness to take calculated risks and tolerating uncertainty in decision making;

- willingness to carry out the tasks by taking additional responsibilities.

Entrepreneur abilities listed above are conducive in pursuing their own economic ambitions. People are looking for entrepreneurial opportunities in order to be better than the competition in conducting investment. An entrepreneur seeking to implement innovative projects is characterized by a high level of analytical thinking, the ability of determining courses of action, and the use of management methods of sales of innovative products and work organization. One must agree with the opinion of Pawlak (2009), who rightly drew attention to the fact that to run a business, it is necessary to have experience, which is not gained overnight but over a lifetime from the moment of taking the first job.

\section{Selected Determinants of Organizational Entrepreneurship}

All entrepreneurial activities are focused on the implementation of new solutions aimed at transforming the previously existing schemes. To be able to achieve high effects resulting from implemented innovations that increase the competitive position of the organization, one must be aware of the determinants affecting the entrepreneurship.

Entrepreneurship is not a one-time and random single action but rather a complex process. As a result of this process, the project that takes many different forms is implemented. The entrepreneurial process is characterized by the logic of the decision-making process and the logic of the project located within the principles of efficient and organized action. The results of entrepreneurial activities are, therefore, determined by the efficiency of decision-making and organization, which provides the necessary resources to run the project, its functioning and efficiency. Although the entrepreneurial process is created by several closely related phases (innovative idea, motivation, means of implementation, implementation, and risk effect), entrepreneurial activity of collecting resources, the formalization of the project, and implementation of the project should be consistent with the logic of efficient performance and do not have to be run in order of stages listed above (Huczek, 2009). 
Entrepreneurial process is influenced by a number of environmental factors which, according to the general classification, were divided into external and internal. External sources of entrepreneurship are related to the processes led by a group of states, national, regional, or local communities. The aim of this part of the article is to analyze factors associated with the development of organizational entrepreneurship. These relate to the specifics of functioning of the company or its organization, work culture, technical, and human resources.

The mission and objectives of the organization play a key role in shaping the entrepreneurial behavior. They define the nature and extent of human activity, which creates the organization. They determine what the objective of the entrepreneur is and why he decided to make innovations. They guide a man in search of needed innovation (Antoszkiewicz, 2013). The mission of the organization indicates the objectives that are becoming increasingly important to the proper functioning of the organization. Their functions are (Kochmańska, 2008):

- to give the direction of the organization;

- to promote effective planning;

- can be a source of motivation for employees;

- conducive to effective evaluation and control.

A special role in the development of entrepreneurship is attributed to human resource management. Its role is to ensure that the organization has a staff with creative attitudes, highly qualified, unique knowledge, able to adapt to the changing environment. Organizational effectiveness does not depend on the number of the staff. That means that the management cannot limit its own activities to supplying the company with employees that it wants the most. One of the primary tasks of human resource management is to create conditions that encourage people to participate actively in the life of the organization (Kopczewski, Pączek, \& Tobolski, 2012). As stated by Huczek (2009), personnel management evolves from catching the interest of employees with objectives and tasks that will change organizational culture and management. It is a response to the problems of integration and activity of employees. These processes in combination with the increase of qualifications cause the staff to participate in more complex processes.

Another factor that should be noted, because of its huge impact on the development of corporate entrepreneurship, is the culture of entrepreneurship. Culture refers to shared values, norms, ideas, beliefs, and expectations to which workers apply. The individual elements of organizational culture act as a system where they strongly influence each other, thus allowing the organization to function (Kopczewski et al., 2012). Depending on the prevailing norms and values that fall within the scope of culture, there are different types of stimulating the entrepreneurship. Therefore, two types of culture are distinguished: entrepreneurial and pro-effective. Each of them has different functions and is a tool to achieve the objectives. Furthermore, it creates the possibility of understanding the mission and strategy of the organization, gets acquainted with objectives and measures to implement them, and thus contributes to the growth of the involvement of members of the organization. Culture increases the chances of reaching an agreement on possible use of resources through which it will be possible to achieve high effects (Koźmiński \& Piotrowski, 2005).

In considering the aspects of culture, authors of the works on organizational entrepreneurship perceived entrepreneurial activities in the context of the entrepreneur's role, which is characterized by the ability to take action during the formation of an organization, to notice opportunities (Bratnicki \& Strużyna, 2011) and to make choices through internal motivation based on values. Bratnicki (2009) had the opinion that entrepreneurs are not robots programmed on business activity and this means that they do not fulfill the function of economic efficiency in a reckless manner. They operate within the human community that is able to define culture, but it 
is worth noting that entrepreneurs are also defined by a culture that builds a network among the same people and between people and the organization. These relationships define the areas of business and focus on taking opportunities, agreeing on contracts, risk evaluation, and sharing this risk as an area that is susceptible to expressed behaviors (Bratnicki \& Gabryś, 2012).

Functioning in a particular social group requires conformity to the public interest. The newly hired employee is influenced by society, so that he can assimilate the values and standards governing organizational behavior. As a result, a new cultural model is formed and it includes socially acceptable behavior as a reaction to a given situation. In the process of interaction through culture, a man develops entrepreneurial attitude by taking an active and conscious participation in decisions concerning the assimilation of behaviors that are necessary for the proper fulfillment of social roles imposed on him. Through the impact the culture has on an individual, an ability to consciously adapt to the environment is developed (Strojny, 2007).

The development of entrepreneurial attitudes is strongly influenced by the style of management. The manager should keep in mind the implementation of tasks required to achieve certain effects, but his own management style must not lead to inhibiting and limiting innovation and implementing changes which often cause chaos in the functioning of the organization. This demonstrates the contradiction occurring between the objectives of effective management and freedom of entrepreneurial employees who are able to use every possible opportunity. In order to not limit them in using their entrepreneurship and to encourage them to take action, certain powers should be delegated to the lower levels of the hierarchy, but it has to be taken into account that the actions of subordinates should be controlled (Czerniałowicz, 2011).

In the creation of entrepreneurial attitudes, proper atmosphere at work is not without significance. As a result, employees will be involved in taking initiative to solve the problems associated with the development of the organization. It is important for the managers to notice and appreciate the creative effort of employees (Glinka \& Gudkova, 2011). Incentive system is crucial in creating the right atmosphere that stimulates entrepreneurship. This concept includes a number of incentives, resources, and conditions available to the organization that aim to persuade employees to change attitudes and to feel the need to adopt an enterprising attitude and engage in professional responsibilities. It is worth remembering that the employee who feels adequately rewarded will engage in work on implementing another innovative solution (Glinka \& Gudkova, 2011). Activation of internal motivation to engage in entrepreneurial activities among the staff depends on the relations among employees. An important determinant of effective cooperation among employees is the willingness to support each other and to cooperate at the level of the team. These actions may lead to increased trust and confidence among individuals exhibiting a sense of entrepreneurship (Kruk, 2013).

More and more often, you can meet with the idea that entrepreneurship is not always closely linked with innate qualities, but it can be developed in the educational process. A school that promotes proactivity and creative thinking and adapts the provided knowledge to the changing environment is important for the development of entrepreneurship. Education at primary school is particularly important. It shapes the personality of a young man and it may affect his subsequent actions and even the prosperity of implemented projects (Groszkowski, 2013).

Current approach to teaching entrepreneurship focuses on finding conditions conducive to the development of entrepreneurial competences. Four "worlds" enhancing the effectiveness of entrepreneurship education were identified. These include entrepreneur, business planning process, ways of thinking, and acting and methods (Balcerak, 2011): 
(1) The world of entrepreneur which should be equipped with a set of specific characteristics. As a part of the curriculum, information about these characteristics is given and it allows to investigate whether the description of his own personality corresponds with entrepreneurial personality;

(2) The world of processes of planning and prediction. In this case, entrepreneurship is seen as a process involving the identification of opportunities, identification of needs, obtaining resources, planning, and implementation;

(3) World of cognition which focuses on entrepreneurial ways of thinking and acting, and how entrepreneurial skills develop. The most important question is: How do people think in an entrepreneurial way? It is a certain kind of education that is based on the analysis and discussion about decision-making processes and cognitive schemas, as well as on work with mental models;

(4) World of methods which in the teaching of entrepreneurship a method of learning by doing is used. Balcerak (2011) believed that the most useful methods are initiating and running a simulated business during classes, simulation games, and reflective practice.

\section{The Impact of Corporate Entrepreneurship on the Efficiency of the Organization}

Management increasingly emphasizes the impact of entrepreneurship on the efficiency of the organization. Researches conducted over the past decades have brought a number of evidences on the positive correlation between these variables. Today, it is believed that entrepreneurial behavior has a positive impact on the results of organization's activities, because it contributes to the growth of profitability. The results of the latest empirical studies indicate that organizations with high entrepreneurial orientation get higher results than those who have low levels of entrepreneurship. This relation is presented by theoretical model of entrepreneurship. Based on the measures of the entrepreneurial orientation, authors of the model came to the conclusion that it has a strong impact on the efficiency of the organization. They also pointed out that a positive correlation between the two is stable over time, which creates the opportunity to gain a permanent position on the market. Some researchers noted the relationship between the dimensions of entrepreneurial orientation and efficiency of the organization, for example, the tendency to take risky actions can be related to efficiency, which shows as a curve in the shape of an inverted $U$. The conclusion is that the organizations characterized by average level of risk-taking are more effective than those whose actions are characterized by taking low or high risk (Zbierowski, 2012).

Innovations have a huge impact on the efficiency of the organization. Implementation of innovations gives organizations the opportunity to grow rapidly. In order to achieve high efficiency, organizations develop new products which allow them to protect themselves from the dangers resulting from actions taken by competitors and are able to respond to emerging market opportunities to ensure success in the form of competitive advantage (Rejman, 2007).

Many researches pointed to the positive relationship between the dynamic ability of an organization and efficiency of its functioning. Due to the contemporary conditions of running a business, there is a need to predict the resources and organizational skills needed in the implementation of creative solutions and to combine them in an unconventional way to generate new sources of value (Bratnicki, 2011).

Several studies revealed the relationship between organizational learning and organizational efficiency. According to Mikuła, Pietruszka-Ortyl, and Potocki (2007), organizational learning is the foundation of an organization focused on entrepreneurship. It is a process where information and knowledge are causing changes 
in previous knowledge of organization that has a significant impact on the changes in human actions and behavior, leading to maintaining a high level of activity, and then the proactivity of changes in the external and internal environment of the organization (Mikuła et al., 2007).

\section{Conclusions}

Entrepreneurship is a unique characteristic of people, which results in the possibility of obtaining economic stability and should therefore be developed among personnel at all levels of the organization and in all organizations, regardless of their business. The implementation of entrepreneurship in management is a proposal for the organizations that want to increase the efficiency of their operations. An appropriate solution for achieving this objective is to engage in shaping the entrepreneurial behavior. By making the best use of human potential and his activity, the organization builds its own competitive advantage in a particular market.

\section{References}

Antoszkiewicz, J. (2013). The role of formulating vision and mission, depending on the market situation for large business organizations. In E. Gołębiowska and K. Raczkowski (Eds.), Management-New perspectives. Entrepreneurship and Management, 14, 17.

Balcerak, A. (2011). Entrepreneurship and entrepreneurial attitude. In J. Skoneczny (Ed.), Shaping innovative, entrepreneurial and creative behavior in engineering education (p. 148). Wrocław: Technical University of Wrocław.

Baron, R. A. (2012). Entrepreneurship. An evidence-based guide. Cheltenham: Edward Elgar.

Bratnicki, M. (2011). Model of entrepreneurial development of organization: The construct and its dimensions. Modern Management, 3, 38.

Bratnicki, M., \& Gabryś, B. (2012). Entrepreneurship once again; capturing opportunities through the prism of communicative interaction. In K. Jaremczuk (Ed.), Determinants of corporate success (p. 229). Przemyśl: State Higher Vocational School.

Bratnicki, M., \& Strużyna, J. (2001). Entrepreneurship and intellectual capital. Katowice: University of Economics in Katowice.

Bratnicki, M. (2009). Deliberations on entrepreneurial development of the organization. Attempt at setting theoretical configuration. In J. Pyka (Ed.), Creativity and innovation in the modernization of industry and services (pp. 7-24). Katowice: Scientific Society of Organizations and Leadership in Katowice.

Bratnicki, M., Zbierowski, P., \& Kozłowski, R. (2007). Factors affecting the development of entrepreneurship in the context of the Global Entrepreneurship Monitor research. In P. Wachowiak, M. Dąbrowski, and B. Majewski (Eds.), Shaping the entrepreneurial attitudes and economic education (p. 269). Katowice: University of Economics in Katowice.

Czerniałowicz, B. (2011). Conditions of corporate entrepreneurship on the example of companies in the West Pomeranian Voivodeship (Studies and works of the Faculty of Economics and Management, Szczecin University, No. 21, p. 202).

Dyduch, W. (2007). Business innovation-The essence, measurement and link with efficiency. In J. Bogdanienko, M. Kuzel, and I. Sobczak (Eds.), Innovative activities of enterprises in a global environment (pp. 30-38). Toruń: Adam Marszałek Publishing House.

Gabryś, B. (2015). The strategic nature of development of entrepreneurial organizations. Retrieved from http://www.ptzp.org.pl/files/konferencje/kzz/artyk_pdf_2011/034.pdf

Glinka, B., \& Gudkova, S. (2011). Entrepreneurship. Warsaw: Wolters Kluwer Business Publishing House.

Groszkowski, T. (2013). Determinants of business development in rural areas. In M. Nowicki (Ed.), Social and organizational factors of development of entrepreneurship (p. 97). Łódź: Technical University of Lodz.

Grzegorczyk, S., \& Romanowska, M. (2002). Entrepreneurship without secrets. Warsaw: WSIP.

Guth, W., \& Ginsberg, A. (1990). Guest editor's introduction: Corporate entrepreneurship. Strategic Management Journal, 4, $5-16$.

Huczek, M. (2009). Management as a factor of development of entrepreneurship. Entrepreneurship and Education, 5, 91.

Klasik, A. (2006). Entrepreneurship, competitiveness and regional development. Katowice: University of Economics in Katowice.

Kochmańska, M. (2008). Success factors of development of entrepreneurship in the management of small and medium-sized enterprises in Matopolskie Voivodship. Retrieved from www.sbc.org.pl/Content/ 10634/kochmanska.pdf 
Kopczewski, M., Pączek, B., \& Tobolski, M. (2012). The essence of organizational culture in the management of a manufacturing company. Retrieved from http://www.ptzp.org.pl/files/konferencje/kzz/artyk_pdf_

Koźmiński, A., \& Piotrowski, W. (2005). Management theory and practice. Warsaw: Polish Economic Publishing House.

Kruk, M. (2013). Grassroots leadership and entrepreneurship employees. In S. Flaszewska, S. Lachiewicz, and M. Nowicki (Eds.), Social and organizational factors of development of entrepreneurship (p. 227). Łódź: Lodz University of Technology.

Mikuła, B., Pietruszka-Ortyl, A., \& Potocki, A. (2007). Basics of enterprise management in a knowledge-based economy. Warsaw: Difin Publishing House.

Nogalski, B., \& Karpacz, J. (2011). Components of entrepreneurial orientation-A case study. Modern Management, 3, 44.

Pawlak, E. (2009). Innovations in organizational culture of micro and small enterprises. In J. Szpon (Ed.), Innovation as a source of competitiveness of the modern enterprise (p. 35). Szczecin: Economicus Publishing House.

Piecuch, T. (2011). Evolution of theory of entrepreneurship - From individual to internal entrepreneurship. In K. Jeremczuk (Ed.), Entrepreneurship conditions -Diversity and unity. Tarnobrzeg: State Higher Vocational School in Tarnobrzeg.

Pinchot, G. (1999). Intrapreneurship. Happer and row. In J. Targalski (Ed.), Entrepreneurship and business development (p. 132). Krakow: University of Economics in Krakow.

Rejman, K. (2007). The impact of innovation on the efficiency of modern enterprises. Entrepreneurship and Education, 3 , 220-224.

Stoner, J., Freeman, R., \& Gibert, S. (2001). Management. Warsaw: Polish Economic Publishing House.

Strojny, J. (2007). Shaping the entrepreneurial mindset-The processes of socialization and self-creation. In P. Wachowiak, M. Dąbrowski, and B. Majewski (Eds.), Shaping the entrepreneurial attitudes and economic education (pp. 207-208). Katowice: University of Economics in Katowice.

Walczak, W. (2010). Measurements and evaluation criteria of entrepreneurship. Economics and Organization of Enterprises, $3,5$.

Zbierowski, P. (2012). Positive orientation of high-performance organization. Warsaw: Wolters Kluwer Business Publishing House.

Żur, A. (2008). Organizational entrepreneurship as a strategy for achieving and maintaining a competitive advantage in the market (Scientific papers of the University of Economics in Krakow, No. 769, p. 73). 